DOEןEKI $12486-11$

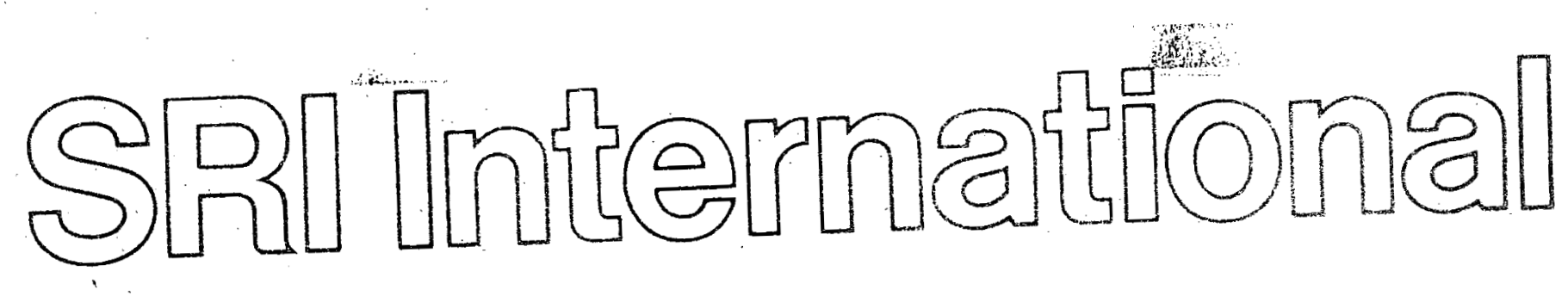

Final Report - January 1992

\title{
CHEMISTRY OF LOWER VALENT ACTINIDE HALIDES
}

K. H. Lau and D. L. Hildenbrand Materials Research and Chemical Engineering Laboratory

SRI Project 7199

Prepared for:

U.S. Department of Energy

Otfice of Basic Energy Sciences

Division of Chemical Sciences

Washington, DC 20585

Attn: Dr. John L. Burnett

Processes \& Techniques Branch

Contract DE-FG03-89ER13986

Approved:

R. Thomas Podoll Laboràtory Director Materials and Chemical Engineering Laboratory

David M. Golden

Vice President

Physical Sciences Division

This document is

PUBLICLY RELEASABLE

Bamstole

Authorizing Official

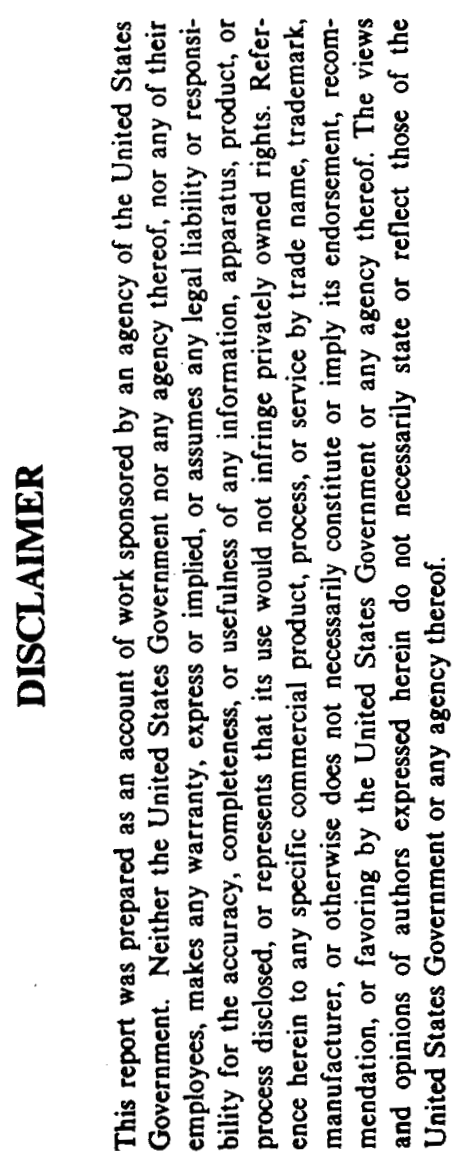

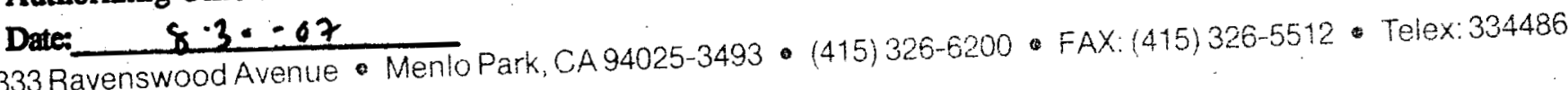

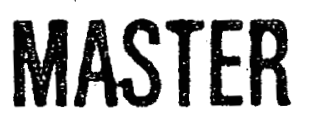




\section{DISCLAIMER}

This report was prepared as an account of work sponsored by an agency of the United States Government. Neither the United States Government nor any agency Thereof, nor any of their employees, makes any warranty, express or implied, or assumes any legal liability or responsibility for the accuracy, completeness, or usefulness of any information, apparatus, product, or process disclosed, or represents that its use would not infringe privately owned rights. Reference herein to any specific commercial product, process, or service by trade name, trademark, manufacturer, or otherwise does not necessarily constitute or imply its endorsement, recommendation, or favoring by the United States Government or any agency thereof. The views and opinions of authors expressed herein do not necessarily state or reflect those of the United States Government or any agency thereof. 


\section{DISCLAIMER}

Portions of this document may be illegible in electronic image products. Images are produced from the best available original document. 


\begin{abstract}
This final report summarizes briefly the scientific results obtained from a DOEsponsored program on the chemistry of some gaseous lower-valent actinide halide species; the program extended over the period 1980 to 1991. The principal focus was on experimental determination of the thermochemical properties of the lower halide and oxyhalide species that are important in the high temperature chemistry of actinide systems. In addition to its use in a number of technological applications, such information is of value in correlating and validating the increasingly useful theoretical techniques for calculation of molecular properties.

This research effort was concerned almost entirely with the first two members of the actinide series, thorium and uranium, although the work was later extended to some aspects of the neptunium-fluorine system in a collaborative program with Los Alamos National Laboratory. Detailed information about the lighter actinides will be helpful in modeling the properties of the heavier actinide compounds, which will be much more difficult to study experimentally. In this program, thermochemical information was obtained from high temperature equilibrium measurements made by effusion-beam mass spectrometry and by effusion-pressure techniques. Data were derived primarily from second-law analysis so as to avoid potential errors in third-law calculations resulting from uncertainties in spectroscopic and molecular constants. This approach has the additional advantage of yielding reaction entropies that can be checked for consistency with various molecular constant assignments for the species involved.

In the U-F, U-Cl, and U-Br systems, all of the gaseous species $\mathrm{UX}, \mathrm{UX}_{2}, \mathrm{UX}_{3}$, $\mathrm{UX}_{4}$, and $\mathrm{UX}_{5}$, where $\mathrm{X}$ represents the halogen, were identified and characterized; the corresponding species $\operatorname{ThX}, \operatorname{Th} X_{2}, \operatorname{Th} X_{3}$, and $T h X_{4}$ were studied in the $T h-F, T h-C l$, and Th-Br systems. A number of oxyhalide species in the systems U-O-F, U-O-Cl, Th-O-F, and $\mathrm{Th}-\mathrm{O}-\mathrm{Cl}$ were studied thermochemically. Additionally, the sublimation thermodynamics of $\mathrm{NpF}_{4}(\mathrm{~s})$ and $\mathrm{NpO}_{2} \mathrm{~F}_{2}$ (s) were studied by mass spectrometry.

Bond dissociation energies in the $\mathrm{Th}-\mathrm{X}$ and $\mathrm{U}-\mathrm{X}$ systems showed some seemingly anomalous trends with ligand number, although their sums are consistent with the known thermochemical properties of the gaseous tetrahalides. Molecular theory may ultimately provide an explanation for this behavior. In any event, the results provide a complete set of standard enthalpies of formation that will be useful in thermodynamic analyses of these
\end{abstract}


systems.

The entropy data gave valuable information on two points. First, the results clarified the magnitudes of the unknown electronic entropies of many of the species. And second, the entropy data strongly suggested that all of the uranium tetrahalide species have distorted tetrahedral structures, while some thorium tetrahalides are regular tetrahedra and some are distorted. Because of the almost complete lack of spectroscopic data on actinide halides, this information will be especially useful.

Other molecular properties such as ionization potentials were also obtained. Overall, the results of this research provide a broad base of thermochemical information for the lighter actinide halides that will be useful in many technological and theoretical applications. 


\section{INTRODUCTION}

This research was undertaken to provide information about the thermochemical and molecular properties of the gaseous lower-valent halide and oxyhalide species of the first several members of the actinide series, primarily thorium and uranium. Although the thermochemistry and spectroscopy of gaseous $\mathrm{UF}_{6}$ were characterized fairly well during the Manhattan Project, only limited information was generated on other uranium halide species. In the intervening years, little new thermochemical information on these species appeared.

As scientists and engineers considered nuclear applications such as fuel processing, safety, and isotope separation, it became clear that the data base of thermochemical and molecular properties needed for planning and analysis was very sketchy and was inadequate for the job at hand. The objective of this research program was to address a portion of the problem dealing with the gaseous sub-halides and oxyhalides of thorium and uranium. The molecular properties sought were the standard enthalpies of formation and bond dissociation energies, the molecular ionization potentials, and the entropies and molecular constants needed in calculating thermal functions. All of this information can be used in evaluating the equilibrium and thermal behavior of neutral and ionized actinide systems over wide temperature ranges. It also provides valuable benchmarks for checking the validity of various $a b$ initio methods for calculation of molecular properties.

The intent of this research was to focus primarily on the first two members of the actinide series, thorium and uranium, since these elements and their compounds are readily obtainable in pure, macroscopic quantities and do not pose any of the difficult handling problems associated with the heavier actinides. A relatively complete thermochemical evaluation of the $T h$ and $U$ halides and oxyhalides can serve as a foundation for later modeling of the thermochemical properties of the heavier actinides, which will be much more difficult to study. In the later stages of this research, the program was extended to the neptunium fluoride and oxyfluoride systems in a collaborative effort with Los Alamos National Laboratory.

Brief descriptions of the experimental techniques and highlights of some of the results are given in the following sections. Publications resulting from this work are listed in the final section. 


\section{EXPERIMENTAL APPROACH}

The primary experimental technique used in this research was effusion-beam mass spectrometry, in which chemical species generated in a heated effusion cell source are identified from the vapor mass spectrum and then monitored by their corresponding ion signals over wide ranges of cell temperature. Species partial pressures and reaction equilibrium constants are evaluated from the measured ion signals and are then used to derive thermodynamic data for the species of interest. Because the spectroscopic and molecular constants needed for third-law analysis of equilibrium data were seldom known, enthalpy data were obtained instead from the temperature dependence of equilibrium constants (second-law method). This approach has the additional advantage of giving reaction entropies that can be examined for compatibility with estimated rotational, vibrational, and electronic level parameters. In this way, the equilibrium data yield the bulk of the information required for detailed thermodynamic analysis of engineering problems.

To complement the mass spectrometric method, which is best suited to measurement of relative pressures, the torsion-effusion method was used for determination of absolute vapor pressures. With this technique, the recoil force associated with molecular effusion is measured by means of a torsion pendulum, and absolute pressures are evaluated from the observed angular deflection and the geometrical and mechanical parameters of the system. Vapor molecular weights, useful in identifying the effusing species, are obtained from simultaneous mass-loss measurements. The mass spectrometric and torsion-effusion techniques together give a relatively complete thermodynamic description of the system under study. These methods have been described in detail in references given in publications resulting from this research. 


\section{RESULTS}

Highlights of some of the results of this research are as follows.

\section{URANIUM HALIDES}

All of the $\mathrm{UX}, \mathrm{UX}_{2}, \mathrm{UX}_{3}, \mathrm{UX}_{4}$, and $\mathrm{UX}_{5}$ gaseous species, where $\mathrm{X}$ is a halogen, were observed and thermochemically characterized in the U-F, U-Cl, and U-Br systems. Molecular ionization potentials accurate to within $0.3 \mathrm{eV}$ or better were obtained for all species. The ionization potentials follow reasonable trends that are in line with the expected electronic structures of the species. Individual bond dissociation energies (BDEs) derived from the reaction enthalpies show that in each system the $\left(\mathrm{X}_{4} \mathrm{U}-\mathrm{X}\right)$ and $\left(\mathrm{X}_{5} \mathrm{U}-\mathrm{X}\right)$ bonds are quite weak relative to those in $\mathrm{UX}_{4}$, giving thermochemical corroboration of the relative instability of the $\mathrm{UX}_{5}$ and $\mathrm{UX}_{6}$ species. Energetically, uranium prefers to be in the tetravalent state, and a heavy penalty in terms of weak bond strengths is paid by forcing it into the pentavalent and hexavalent states.

Although the U-F, U-Cl, and U-Br systems each showed this sharp drop in thermodynamic stability for the pentavalent and hexavalent states, the (U-F), (FU-F), $\left(F_{2} \mathrm{U}-\mathrm{F}\right)$, and $\left(\mathrm{F}_{3} \mathrm{U}-\mathrm{F}\right)$ BDEs showed a dramatically different progression than those of the corresponding chlorides and bromides; the $\mathrm{Cl}$ and $\mathrm{Br}$ patterns were quite similar. The seemingly anomalous behavior of the fluorides was confirmed by a series of independent measurements. At present we have no explanation for the unusual BDE patterns, but future high-level theoretical calculations may provide some answers.

Vapor entropies derived from the equilibrium data were compared with values calculated by statistical methods for certain assignments of spectroscopic and molecular constants. The comparisons showed very clearly that the UX monohalide species have electronic entropies very similar to that of atomic $U$, so that binding of the first halogen ligand does not significantly split the atomic levels; the electronic contributions of the polyatomic species decrease regularly with both the number of halogen ligands and the mass of the ligand. Representative vibrational frequency assignments, compatible with the experimental entropies, were estimated for all species from fragmentary data on $\mathrm{UF}_{6}$ and some of the tetrahalides. From the entropy comparisons, a reliable set of molecular constants was developed for use in calculating thermal functions. 
Interestingly, the experimental entropies of gaseous $\mathrm{UF}_{4}, \mathrm{UCl}_{4}$, and $\mathrm{UBr}_{4}$ were found to be incompatible with regular tetrahedral structures of $T_{d}$ symmetry. However, the entropies are compatible with a less symmetrical configuration such as $\mathrm{C}_{2 \mathrm{v}}$. Conflicting structural information from electron diffraction, infrared spectroscopy, photoelectron spectroscopy, and theoretical calculations indicated the possibility of both regular tetrahedral and distorted tetrahedral structures but was not conclusive. The thermodynamic data provide both a different perspective and a strong stimulus to resolve the problem by a definitive, new structural determination.

The results are described in detail in Publications 1, 2, 5, 13, and 14 (listed in the final section of this report).

\section{THORIUM HALIDES}

Similarly, each of the gaseous species $\mathrm{ThX}, \mathrm{ThX} 2, \mathrm{ThX} \mathrm{X}_{3}$, and $\mathrm{ThX} \mathrm{X}_{4}$ in the Th-F, $\mathrm{Th}-\mathrm{Cl}$, and $\mathrm{Th}-\mathrm{Br}$ systems was identified by mass spectrometry and studied thermochemically. The BDEs in the Th-F and Th-Cl systems followed the pattern $\mathrm{D}(\mathrm{Th}-\mathrm{X})$ $\cong D\left(X_{2}\right.$ Th $\left.-X\right) \cong D\left(X_{3}\right.$ Th $\left.-X\right)<D(X T h-X)$. However, the Th-Br system followed the quite different pattern $\mathrm{D}\left(\mathrm{Br}_{3} \mathrm{Th}-\mathrm{Br}\right)>\mathrm{D}\left(\mathrm{Br}_{2} \mathrm{Th}-\mathrm{Br}\right)>\mathrm{D}(\mathrm{BrTh}-\mathrm{Br})>\mathrm{D}(\mathrm{Th}-\mathrm{Br})$. In addition, $\mathrm{D}\left(\mathrm{Br}_{3} \mathrm{Th}-\mathrm{Br}\right) \cong \mathrm{D}\left(\mathrm{Cl}_{3} \mathrm{Th}-\mathrm{Cl}\right)$, which is unusual in that specific metal-halogen bond strengths nearly always show a significant decrease with increasing mass of the halogen ligand. This relationship may signal some type of change in the Th- $\mathrm{X}$ bonding in passing from the fluorides and chlorides to the bromides. The bond strength sums in the tetrahalides are all internally consistent with other data on the $\mathrm{ThX}_{4}$ species, indicating that there are no significant errors in the individual BDE values. Here, too, theoretical calculations may yield some insight, if the calculations are sufficiently high-level.

Reaction entropies again provided useful information about spectroscopic and molecular constant assignments. Remarkably, comparison of experimental and calculated values at $2200 \mathrm{~K}$ showed the Th monohalide species to have nearly identical electronic entropies that are comparable to that of atomic Th. This behavior is very similar to that of the $\mathrm{U}$ monohalides. The results indicate no significant electronic entropies for the $\mathrm{Th} \mathrm{X}_{2}$ and $T h \mathrm{X}_{4}$ species but are compatible with a small electronic contribution of about $R \ln 2$ for the $\mathrm{Th} \mathrm{X}_{3}$ species. Consistent vibrational frequency assignments, which required revision of some literature estimates, were developed for all of the molecular species.

The entropies of the gaseous tetrahalides, derived from sublimation pressure measurements on the solid phases, showed an interesting trend. Although the entropies of 
both $\mathrm{ThF}_{4}$ and $\mathrm{ThCl}_{4}$ are in close accord with tetrahedral symmetry, those of $\mathrm{ThBr}_{4}$ and $\mathrm{ThI}_{4}$ are definitely more compatible with a lower symmetry such as $\mathrm{C}_{2 \mathrm{v}}$. Such a structural change in the middle of a halide series is quite an unexpected result. Since there have been no clear structural determinations on gaseous $\mathrm{ThBr}_{4}$ and $\mathrm{ThL}_{4}$, some type of definitive measurement would be very desirable.

A detailed description of the work is given in publications 9, 11, 12, and 14 (listed below).

\section{URANIUM AND THORIUM OXYHALIDES}

A mass spectrometric and torsion-effusion study of the sublimation of $\mathrm{UO}_{2} \mathrm{~F}_{2}(\mathrm{c})$ showed that $U F_{5}$ and $U O_{2} F_{2}$ are the major gaseous species at equilibrium; lesser amounts of gaseous $\mathrm{UF}_{4}$ and $\mathrm{UOF}_{4}$ were also observed, showing that the sublimation chemistry is exceedingly complex. The results also showed that previous studies were incorrect in deducing that $\mathrm{UF}_{6}$ is the major gaseous product. New thermochemical data were derived for $\mathrm{UO}_{2} \mathrm{~F}_{2}$ and $\mathrm{UOF}_{4}$; in particular, an accurate sublimation entropy was useful in estimating reliable spectroscopic and molecular constants for $\mathrm{UO}_{2} \mathrm{~F}_{2}(\mathrm{~g})$. On the other hand, similar studies of $\mathrm{UO}_{2} \mathrm{Cl}_{2}$ (c) showed $\mathrm{Cl}_{2}(\mathrm{~g})$ to be the only detectable vapor species, with several step-wise sublimation reactions ending in $\mathrm{UO}_{2}$ (c). It was not possible to clearly identify the intermediate $\mathrm{U}-\mathrm{O}-\mathrm{Cl}$ solid phases. A study of the dissociative vaporization of $\mathrm{ThOF}_{2}(\mathrm{c})$ to $\mathrm{ThF}_{4}(\mathrm{~g})$ and $\mathrm{ThO}_{2}(\mathrm{c})$ gave new thermochemical data for the crystalline oxyfluoride.

Gas-solid reaction studies of $\mathrm{UO}_{2}(\mathrm{c})+\mathrm{UF}_{6}(\mathrm{~g}), \mathrm{UO}_{2}(\mathrm{c})+\mathrm{Cl}_{2}(\mathrm{~g})$ and $\mathrm{ThO}_{2}(\mathrm{c})+$ $\mathrm{Cl}_{2}(\mathrm{~g})$ with mass spectrometric detection led to identification of the species $\mathrm{UOF}, \mathrm{UOF}_{2}$, $\mathrm{UO}_{2} \mathrm{~F}, \mathrm{UOCl}, \mathrm{UOCl}_{2}, \mathrm{UO}_{2} \mathrm{Cl}, \mathrm{ThOCl}$, and $\mathrm{ThOCl}_{2}$. The fluorination of Th(s) containing an oxygen impurity also led to identification of $\operatorname{ThOF}(\mathrm{g})$. Most of these species were studied thermochemically, and correlations can be developed to estimate the properties of other gaseous oxyhalides from the known thermochemistry of the halides and oxides.

These studies are described in Publications 4, 9, and 18.

\section{NEPTUNIUM FLUORIDE AND OXYFLUORIDE}

To extend these studies to the heavier actinides, a collaboration was initiated with Dr. P. D. Kleinschmidt of Los Alamos National Laboratory (LANL) so as to use the equipment and special safe-handling facilities available there. In work done in conjunction with Dr. Kleinschmidt, the sublimation behavior of $\mathrm{NpF}_{4}(\mathrm{c})$, and also of $\mathrm{NpO}_{2} \mathrm{~F}_{2}(\mathrm{c})$, was 
studied with the quadrupole mass filter and Knudsen cell source in use for other actinide studies at LANL. The samples were prepared at LANL.

Only $\mathrm{NpF}_{4}(\mathrm{~g})$ was observed in the effusing vapor with both $\mathrm{NpF}_{4}(\mathrm{c})$ and $\mathrm{NpO}_{2} \mathrm{~F}_{2}$ (c); new thermochemical data were derived for the gaseous tetrafluoride. Unlike the corresponding uranium system, in which several U-O-F species were characterized, no gaseous oxyfluorides were observed over $\mathrm{NpO}_{2} \mathrm{~F}_{2}(\mathrm{c})$. From the difference in the $\mathrm{NpF}_{4}(\mathrm{~g})$ pressures over the crystalline tetrafluoride and oxyfluoride, the enthalpy of formation of $\mathrm{NpO}_{2} \mathrm{~F}_{2}(\mathrm{c})$ was evaluated.

Several attempts were made to study the sublimation of $\mathrm{NpF}_{4}$ (c) under reducing conditions in order to characterize the lower-valent species $\mathrm{NpF}_{3}, \mathrm{NpF}_{2}$, and $\mathrm{NpF}$. To date, however, these experiments have been unsuccessful, and no information was obtained on the subfluorides.

Accounts of these studies are given in Publications 16 and 17.

\section{GASEOUS ACTINIDE IONS}

As part of a collaborative project with L. V. Gurvich and V.S. Yungman of the Institute for High Temperatures, Academy of Sciences, USSR, under the auspices of the International Atomic Energy Agency, thermodynamic data for gaseous actinide ions were reviewed and compiled. Ionization energies for the atomic ions and many of the molecular ions were included. Thermal functions were tabulated for the singly charged atomic ions $\mathrm{Th}^{+}$through $\mathrm{Cf}^{+}$, using electronic energy levels obtained from Dr. J. Conway of Lawrence Berkeley Laboratory. Thermodynamic data for a number of the actinide subhalide neutral species were also reviewed and compiled. The results are summarized in Publication 3.

\section{MISCELLANEOUS}

In connection with the reprocessing of nuclear fuels and the possible vapor phase transport of fission product ruthenium, the high temperature chemistry of the Ru-F system was studied. All of the species $\mathrm{RuF}_{4}, \mathrm{RuF}_{3}, \mathrm{RuF}_{2}$, and $\mathrm{RuF}$ were identified and characterized thermochemically. Also, for use as a reaction partner in evaluating the thermochemistry of metal bromide reactions, the thermodynamics of the diatomic species $\mathrm{AlBr}$ was determined from high temperature equilibrium measurements. Results are detailed in Publications 7 and 10. 


\section{PUBLICATIONS}

1. "Thermochemical Properties of the Gaseous Lower Valent Fluorides of Uranium," K. H. Lau and D. L. Hildenbrand, J. Chem. Phys. 76, 2646 (1982).

2. "Thermochemical Studies of the Gaseous Uranium Chlorides," K. H. Lau and D. L. Hildenbrand, J. Chem. Phys. 80, 1312 (1984).

3. The Chemical Thermodynamics of Actinide Elements and Compounds, Part 13. The Gaseous Actinide Ions, D. L. Hildenbrand, L. V. Gurvich, and V. S. Yungman, International Atomic Energy Agency, Vienna, 1985.

4. "The Complex Sublimation/Decomposition of Uranyl Fluoride; Thermodynamics of Gaseous $\mathrm{UO}_{2} \mathrm{~F}_{2}$ and $\mathrm{UOF}_{4}, " \mathrm{~K}$. H. Lau, R. D. Brittain, and D. L. Hildenbrand, J. Phys. Chem. 89, 4369 (1985).

5. "Thermochemistry of the Gaseous Uranium Bromides, UBr through UBr 5 ," K. H. Lau and D. L. Hildenbrand, J. Chem. Phys. 86, 2949 (1987).

6. "Equilibrium Measurements as a Source of Entropies and Molecular Constant Information", D.L. Hildenbrand, Pure Appl. Chem. 60, 303 (1988).

7. "High Temperature Chemistry of the Gaseous Ruthenium Fluorides," D. L. Hildenbrand and K. H. Lau, J. Chem. Phys. 89, 5825 (1988).

8. "Decomposition Pressure and Thermodynamic Stability of Thorium Oxyfluoride," K. H. Lau and D. L. Hildenbrand, J. Phys. Chem. 93, 3786 (1989).

9. "High Temperature Thermodynamic Studies of Some Gaseous Thorium Fluorides", K.H. Lau, R.D. Brittain, and D.L. Hildenbrand, J. Chem. Phys. 90, 1158 (1989).

10. "Dissociation Energy of the Molecule AlBr from Equilibrium Measurements," D. L. Hildenbrand and K. H. Lau, J. Chem. Phys. 91, 4909 (1989).

11. "High Temperature Equilibrium Studies of the Gaseous Thorium Chlorides," K. H. Lau and D. L. Hildenbrand, J. Chem. Phys. 92, 6124 (1990).

12. "Thermochemistry of the Gaseous Thorium Bromides," D. L. Hildenbrand and K. H. Lau, J. Chem. Phys. 93, 5983 (1990).

13. "Redetermination of the Thermochemistry of Gaseous $\mathrm{UF}_{5}, \mathrm{UF}_{2}$, and UF," D. L. Hildenbrand and K. H. Lau, J. Chem. Phys. 94, 1420 (1991).

14. "The Entropies and Probable Symmetries of the Gaseous Thorium and Uranium Tetrahalides," D. L. Hildenbrand and K. H. Lau, J. Chem. Phys. 94, 8270 (1991).

15. "Trends and Anomalies in the Thermodynamics of Gaseous Thorium and Uranium Halides," D. L. Hildenbrand, Pure Appl. Chem. In press. 
16. "Sublimation Studies of $\mathrm{NpF}_{4}$, " P. D. Kleinschmidt, K. H. Lau, and D. L. Hildenbrand, accepted for publication in J. Chem. Phys.

17. "Sublimation Studies of $\mathrm{NpO}_{2} \mathrm{~F}_{2}$," P. D. Kleinschmidt, K. H. Lau, and D. L. Hildenbrand, submitted to J. Chem. Phys.

18. "Thermochemistry of Some Gaseous U-O-F and U-O-Cl Species," D. L. Hildenbrand and K. H. Lau, In preparation. 